\title{
Quantifying the disparity in outcome between urban and rural patients with acute appendicitis in South Africa
}

\author{
V Y Kong, ${ }^{1} \mathrm{MB}$ ChB; S van de Linde, ${ }^{2} \mathrm{MSc} ; \mathrm{C}$ Aldous, ${ }^{3} \mathrm{PhD} ; \mathrm{J}$ J Handley, ${ }^{4}$ FCA (SA); D L Clarke, ${ }^{1}$ FCS (SA) \\ ${ }^{1}$ Department of Surgery, Nelson R Mandela School of Medicine, University of KwaZulu-Natal, Durban, South Africa \\ ${ }^{2}$ Department of Public Health, Programme for Bioethics and Biostatistics, College of Heath Sciences, University of KwaZulu-Natal, Duban, South Africa \\ ${ }^{3}$ School of Clinical Medicine, Nelson R Mandela School of Medicine, University of KwaZulu-Natal, Durban, South Africa \\ ${ }^{4}$ Department of Anaesthetics and Critical Care, Nelson R Mandela School of Medicine, University of KwaZulu-Natal, Durban, South Africa
}

Corresponding author: D L Clarke (damianclar@gmail.com)

Background. Acute appendicitis in South Africa is associated with higher morbidity than in the developed world.

Objective. To compare outcomes of urban and rural patients in KwaZulu-Natal and to determine whether there are disparities in outcome. Methods. We conducted a prospective study from September 2010 to September 2012 at Edendale Hospital in Pietermaritzburg, South Africa. All patients who presented with acute appendicitis were included. The operative and clinical course of urban and rural patients was compared. Results. A total of 500 patients were included, with 200 patients in the rural group and 300 in the urban group. Those from the rural group had a significantly longer duration of symptoms prior to presentation. All septic parameters were significantly worse in the rural group. Significantly more patients from the rural group required a laparotomy ( $77 \%$ v. $51 \%$ urban; $p<0.001)$. Inflamed, non-perforated appendicitis was more commonly seen in the urban group $(52.3 \%$ v. $21 \%$ rural; $p<0.001)$, while perforated appendicitis was much more common in the rural group ( $79 \%$ v. $47.7 \%$ urban; $p<0.001$ ). Perforation associated with generalised, four-quadrant intra-abdominal contamination was significantly higher in the rural group than the urban group $(60.5 \%$ v. $21 \%$, respectively; $p<0.05)$. Significantly more patients from the rural group required an open abdomen $(46 \%$ v. $12 \%$ urban; $p<0.001)$ and $\geq 1$ re-laparotomies to control severe intra-abdominal sepsis $(60.5 \% \mathrm{v}$. $23.3 \%$ urban; $p<0.001)$.

Conclusion. We have identified rural origin as an independent indicator of poor outcome. Possible reasons may include difficulty in accessing the health system or delay in transfer to a regional hospital. These need to be investigated further.

S Afr Med J 2013;103(10):742-745. DOI:10.7196/SAMJ.7109 


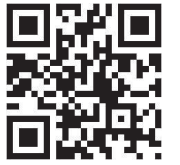

There are significant disparities in access to surgical care across countries in the world, as well as between regions within countries and between groups of patients. ${ }^{[1]}$ These disparities in access to care often translate into differences in outcome. ${ }^{[2]}$ We have previously published our experience with acute appendicitis in South Africa (SA) and have shown that there are significant delays in accessing care with an associated perforation rate of $54 \% .{ }^{[3]}$ This is in keeping with other SA audits, which report similar rates ranging from $43 \%$ to $51 \%{ }^{[4]}$ The equivalent perforation rate in the developed world is less than half of that in SA. ${ }^{[3]}$

\section{Objective}

To determine whether disparities in outcome between SA and the developed world were reflected in both urban- and rural-based patients in SA.

\section{Methods}

We conducted a prospective study from September 2010 to September 2012 at Edendale Hospital in Pietermaritzburg, KwaZulu-Natal (KZN). Edendale Hospital drains 2 health districts, namely the rural Sisonke District and the urban uMgungundlovu District. Patients who presented from uMgungundlovu District were classified as urbanbased patients. Those who presented from 1 of the 4 rural hospitals in Sisonke District were classified as rural-based patients. All patients who presented with a clinical diagnosis and intraoperative confirmation of acute appendicitis were included. Assessment of the diagnosis was made on purely clinical grounds; advance imaging was not utilised. All patients with an alternative intraoperative diagnosis were excluded. Basic demographic data were collected. Each patient was specifically asked about his/her health-seeking behaviour, including the duration of symptoms prior to contact with the healthcare system. Clinical symptoms, physical examination findings, baseline vital signs and results of laboratory tests were recorded. Details of operative findings were obtained from the operative records. The clinical course of each patient to discharge (or death) was followed. Admission to the intensive care unit (ICU), the need for 're-look' laparotomy, major complications and death were recorded. Patients in the rural-based group were then compared with the urban-based cohort.

Ethics approval was obtained from the uMgungundlovu Health Review Board.

\section{Statistical analysis}

The Pearson $\chi^{2}$ test was used when the sample size assumption was adhered to. Fischer's exact test was utilised in cases where the $\chi^{2}$ assumption was not fulfilled and Mann-Whitney $U$ tests were performed to identify any significant difference between the 2 patient cohorts after the data distributions were proved to be asymmetrical. Non-parametric (asymmetrical) data were described in terms of median and interquartile range (IQR). Statistical significance was considered when $p<0.05$. All statistical analysis was performed using SPSS version 19.

\section{Results}

During the study period, a total of 500 patients presented with acute appendicitis. There were 200 patients in the rural and 300 in the urban cohorts. Results are summarised in Table 1.

\section{Basic demographics}

The mean age of patients in the rural v. urban groups was not statistically significantly different ( $18 \mathrm{v}$. 19 years, respectively; $p=0.8$ ). Of the 200 patients in the rural group, males comprised $57 \%$
$(114 / 200)$ and females $43 \%(86 / 200)$. Of the 300 urban patients, there were more males $73 \%(202 / 300)$ and fewer females $33 \%(98 / 300)$ (rural v. urban for both males and females, $p=0.02$ ).

\section{Clinical presentations}

Rural-based patients had a significantly longer duration of symptoms with a median of 6 days (IQR 3 - 9) prior to presentation when compared with the median duration of 3 days in urban patients (IQR 2 - 4; rural v. urban; $p<0.001$ ). Comparison of clinical features present on admission was as follows (rural v. urban patients, respectively): anorexia $70.5 \%$ v. $69 \%$; nausea and vomiting $80.5 \%$ v. $79 \%$; migratory abdominal pain $28 \%$ v. $32.3 \%$; non-migratory abdominal pain $71.5 \%$ v. $67.7 \%$; dysuria $2 \%$ v. $3.3 \%$; diarrhoea $4.5 \%$ v. $8.8 \%$; and constipation $7 \%$ v. $5.3 \%$. Differences were not statistically significant. However, significantly more patients in the rural group had generalised peritonitis on presentation $(59 \%, 118 / 200$ v. $20 \%, 60 / 300$ urban; $p<0.001)$; significantly more patients in the urban group had localised peritonitis $(80 \%, 240 / 300$ v. $41 \%, 82 / 200$ rural; $p<0.001)$. Other clinical parameters (rural v. urban, respectively) including the median temperature $\left(37.9^{\circ} \mathrm{C}\right.$, IQR 37 - 38.4 v. $37.2^{\circ} \mathrm{C}$, IQR 36.9 - 38; $\left.p<0.001\right)$, heart rate (103 bpm, IQR 90.5 - 120 v. 99 bpm, IQR 88 - 109; $p<0.001$ ) and total leukocyte counts $\left(15.6 \times 10^{9} / \mathrm{l}\right.$, IQR $12-20$ v. $13.9 \times 10^{9} / \mathrm{l}$, IQR 11 - 15.5; $p<0.001)$ were significantly higher in the rural group.

\section{Operative findings}

Significantly more patients from the rural group required a laparotomy ( $77 \%$ v. $51 \%$ urban; $p<0.001$ ) as the initial choice of surgical access, while relatively more patients from the urban group required a local incision ( $49 \%$ v. $23 \%$ rural; $p<0.001$ ). Highly significant differences were found at operation. An inflamed, non-perforated appendix was more commonly found intraoperatively in the urban group $(52.3 \% \mathrm{v}$. $21 \%$ rural; $p<0.001)$. A perforated appendix was much more common in the rural group (79\% v. $47.7 \%$ urban; $p<0.001)$. Of those patients in whom the appendix had perforated, intra-abdominal contamination was more frequently localised in the urban group $(26.7 \%$ v. $18.5 \%$ rural; $p=0.04)$, in contrast to the rural group where significantly higher perforation $(60.5 \%$ v. $21 \%$ urban; $p<0.001)$ associated with generalised, four-quadrant intra-abdominal contamination was observed.

\section{Clinical course}

The majority of patients in the urban group were managed in the general ward $(97.7 \%$ v. $77 \%$ rural; $p<0.001)$. The need for ICU admission was 10 times higher in the rural group $(23 \%$ v. $2.3 \%$ urban; $p<0.001)$. The median overall length of hospital stay was also significantly longer in the rural group (8 days, IQR 3 - 15 v. 4 days, IQR 2 - 7 urban; $p<0.001)$. Significantly more patients in the rural group required an open abdomen $(46 \%$ v. $12 \%$ urban; $p<0.001)$ and required $\geq 1$ re-laparotomies to control severe intra-abdominal sepsis (60.5\% v. $23.3 \%$ urban; $p<0.001)$.

\section{Complications}

The overall complication rate was significantly higher in the rural group ( $35 \%$ v. $11 \%$ urban; $p<0.001)$. Considered separately, each of the following was significantly higher in the rural group (rural v. urban, respectively): hospital-acquired pneumonia $(21.5 \%$ v. $5 \%$; $p<0.001)$, renal failure ( $14 \%$ v. $0.7 \% ; p<0.001)$, wound sepsis $(22.5 \%$ v. $6.7 \% ; p<0.001)$ and other miscellaneous conditions $(5.5 \%$ v. $0.3 \%$; $p<0.001)$. The overall mortality was significantly higher among ruralbased patients than urban-based patients $(3.5 \%$ v. $0.3 \%$, respectively; $p=0.008)$. 
Table 1. Outcomes of rural v. urban patients with acute appendicitis in South Africa

\begin{tabular}{|c|c|c|c|}
\hline Characteristics & Rural $(N=200)$ & Urban $(N=300)$ & $p$-value \\
\hline \multicolumn{4}{|l|}{ Demographics } \\
\hline Male, $n(\%)$ & $114(57)$ & $202(67.3)$ & 0.02 \\
\hline Female, $n(\%)$ & $86(43)$ & $98(32.7)$ & 0.02 \\
\hline Age (years), median (range) & $18(12-29)$ & $19(13-27)$ & 0.8 \\
\hline Duration (days), median (range) & $6(3-9)$ & $3(2-4)$ & $<0.001$ \\
\hline \multicolumn{4}{|l|}{ Clinical features, $n(\%)$} \\
\hline Anorexia & $141(70.5)$ & $207(69)$ & 0.72 \\
\hline Nausea, vomiting & $161(80.5)$ & $237(79)$ & 0.68 \\
\hline Migratory pain & $56(28)$ & $97(32.3)$ & 0.3 \\
\hline Non-migratory pain & $143(71.5)$ & $203(67.7)$ & 0.36 \\
\hline Dysuria & $4(2)$ & $10(3.3)$ & 0.38 \\
\hline Diarrhoea & $9(4.5)$ & $24(8)$ & 0.12 \\
\hline Constipation & $14(7)$ & $16(5.3)$ & 0.44 \\
\hline Localised peritonitis & $82(41)$ & $240(80)$ & $<0.001$ \\
\hline Generalised peritonitis & $118(59)$ & $60(20)$ & $<0.001$ \\
\hline \multicolumn{4}{|l|}{ Baseline vital signs, mean (range) } \\
\hline Temperature $\left({ }^{\circ} \mathrm{C}\right)$ & $37.9(37-38.4)$ & $37.2(36.9-38)$ & $<0.001$ \\
\hline Heart rate (bpm) & $103(91-120)$ & $99(88-109)$ & $<0.001$ \\
\hline Leukocyte count $\left(\times 10^{9}\right)$ & $15.6(12-20)$ & $13.9(11-15.5)$ & $<0.001$ \\
\hline \multicolumn{4}{|l|}{ Surgical access, $n(\%)$} \\
\hline Local incision & $46(23)$ & $147(49)$ & $<0.001$ \\
\hline Laparotomy & $154(77)$ & $153(51)$ & $<0.001$ \\
\hline \multicolumn{4}{|l|}{ Operative findings, $n(\%)$} \\
\hline Inflamed appendix & $42(21)$ & $157(52.3)$ & $<0.001$ \\
\hline Perforated appendix & $158(79)$ & $143(47.7)$ & $<0.001$ \\
\hline Localised contamination & $37(18.5)$ & $80(26.7)$ & 0.04 \\
\hline Generalised contamination & $121(60.5)$ & $63(21)$ & $<0.001$ \\
\hline \multicolumn{4}{|l|}{ Clinical course } \\
\hline Ward admission, $n(\%)$ & $154(77)$ & $293(97.7)$ & $<0.001$ \\
\hline ICU admission, $n(\%)$ & $46(23)$ & $7(2.3)$ & $<0.001$ \\
\hline Total hospital stay (days), mean (range) & $8(3-13)$ & $4(2-7)$ & $<0.001$ \\
\hline Open abdomen, $n(\%)$ & $92(46)$ & $36(12)$ & $<0.001$ \\
\hline Re-laparotomy, $n(\%)$ & $121(60.5)$ & $70(23.3)$ & $<0.001$ \\
\hline \multicolumn{4}{|l|}{ Complications, $n(\%)$} \\
\hline Pneumonia & $43(21.5)$ & $15(5)$ & $<0.001$ \\
\hline Renal failure & $28(14)$ & $2(0.7)$ & $<0.001$ \\
\hline Wound sepsis & $45(22.5)$ & $20(6.7)$ & $<0.001$ \\
\hline Other & $11(5.5)$ & $1(0.3)$ & $<0.001$ \\
\hline Death & $7(3.5)$ & $1(0.3)$ & 0.008 \\
\hline
\end{tabular}

\section{Discussion}

Acute appendicitis is the most common surgical emergency worldwide. The natural history of appendicitis is one of progression from inflammation to perforation and on to diffuse abdominal sepsis. ${ }^{[5]}$ of appendicular rupture, and subsequently much more problematic clinical outcomes than in the developed world. ${ }^{[3,4]}$ Generally, costs and length of hospital stay are all significantly longer in patients who experience appendicular rupture. ${ }^{[7]}$ Appendicular rupture is associated with the need for re-laparotomy, temporary abdominal closure and ICU admission. ${ }^{[3]}$ Our previous work demonstrated a significant disparity in outcome between patients in SA and those in the developed world. [3] Our current study extends this insight by demonstrating a disparity in outcome between urban- and rural-based patients within SA. Rural patients had a much longer delay between the onset of symptoms and seeking healthcare than urban patients. Consequently, when they did arrive at the regional hospital they were more ill and more likely to have diffuse peritonitis. In turn, they were more likely to require a laparotomy and ICU admission postoperatively. Rural patients were disproportionately more likely to be managed with temporary abdominal closure and re-laparotomy. They were more likely to develop acute renal failure.

Acute appendicitis is a time-sensitive pathology. ${ }^{[5]}$ Once the disease process commences, progression to end-stage disease is relentless unless there is appropriate surgical intervention. ${ }^{[7]}$ A number of milestones in each patient's narrative are important, including the onset of abdominal pain, parental or patient recognition of the potential urgency of the illness and timely health-seeking behaviour followed by clinical recognition of potential acute appendicitis, appropriate referral and surgical intervention. Variations in these milestones account for the disparate outcomes. SA reports on appendicitis have almost exclusively focused on black patients. ${ }^{[3]}$ However, within the developed world, there are disparities in the outcome of acute appendicitis. Studies from the USA have demonstrated several associations between increased rates of appendicular rupture and variables such as method of payment, access to primary care, source of referral and ethnicity. ${ }^{[8,9]}$ Higher rupture rates have been reported in ethnic minority children, younger children, children with addresses from socioeconomically poorer ZIP codes, children who lack private insurance and children referred from somewhere other than a dedicated emergency department. ${ }^{[10]}$ In our study cohorts, rural patients fared significantly worse than their urban counterparts. Both groups were black, thus eliminating issues of ethnicity or cultural practices as an explanation for disparate outcomes. Rural origin of the patient emerges 
as an independent risk factor for appendicular rupture. The most striking underlying difference between the urban- and rural-based groups is the prolonged delay between onset of symptoms and accessing the healthcare system on the part of the latter. The risk of appendicular perforation and subsequent complications is proportional to the time between onset of symptoms and surgical intervention.

The rural communities in SA remain some of the most impoverished areas in the world. ${ }^{[11]}$ However, poor health outcome in rural areas is not solely confined to SA. A significant body of literature demonstrates disparity in outcomes between urban and rural patients in developed countries with sizable rural populations such as Australia, Canada and the USA. ${ }^{[12]}$ Reasons for this disparity are multifaceted. There are several common problems faced by rural areas throughout the world. They are plagued with chronic understaffing of hospitals and high staff turnover and lack specialist and radiological imaging and laboratory services. The remoteness of rural areas means that there are long delays in accessing healthcare and further delays may be associated with the transfer of these patients to higher levels. ${ }^{[13]}$ Moreover, there is a shortage of basic general surgical services for rural communities throughout the world. ${ }^{[14]}$

Patients from the rural areas remote from surgical centres may experience difficulties in accessing appropriate services. ${ }^{[15]}$ These difficulties are referred to as 'barriers to care' and authors have suggested various systems to classify these. ${ }^{[16]}$ The classification scheme described by Grimes et al. ${ }^{[16]}$ defines 3 categories: cultural (acceptability), financial (affordability) and structural (accessibility). For pragmatic and quality-improvement reasons it is useful to divide barriers to care into pre-contact (with the health system) and postcontact factors. Pre-contact factors include health-seeking behaviour, cultural factors and issues of access and affordability, while postcontact factors include delays in the recognition of the disease and delays in transfer and referral.

Health-seeking behaviour is influenced by gender, education and socioeconomic status. ${ }^{[17]}$ Patients may expect spontaneous resolution of symptoms and hence delay seeking healthcare. ${ }^{[18]}$ Although access to primary care is free, the perceived potential for hospital admission and subsequent loss of ability to work or missed school days potentially prevented many patients from seeking medical attention. Children may experience further delays due to lack of responsible carers. ${ }^{[17]} \mathrm{KZN}$ Province covers a vast area and has a large rural population. Within the rural Sisonke District and the urban uMgungundlovu District covered by our surgical unit, there are series of local polyclinics and 4 peripheral hospitals serving the local population. There are still significant problems with access to the local polyclinics, as substantial travelling is usually required.

Of concern is the issue of delayed recognition of the disease once the patient has presented to the health system. Rural facilities in Sisonke District have staff of varied levels of experience. ${ }^{[19]}$ Almost no abdominal general surgery ${ }^{[20]}$ is undertaken at these rural district hospitals; all patients with acute appendicitis are referred to the regional hospital for further assessment, thus creating two further potential delays - in diagnosis/recognition (it is not uncommon for patients to be sent home from a healthcare institution on several occasions with an incorrect diagnosis (authors' personal observations)) and in transportation from a district to a regional hospital for surgery.

\section{Conclusion}

This survey identifies rural origin as an independent risk factor for appendicular rupture and a poor clinical course. Rural patients have major delays between the onset of symptoms and definitive surgery compared with urban patients. The exact reasons for these delays require further investigation. Health-seeking behaviour is complex and is influenced by rural poverty and remoteness as well as cultural issues such as the reliance on traditional healers as a primary source of care and health advice.

However, failure of clinical recognition once contact with the health system has been made followed by delays in transfer for surgery to the regional hospital are failings of the health system. Intervention is urgently needed to improve the outcomes of acute appendicitis among rural patients, following further research aimed at quantifying the relative contributions of patient behaviour and the failings of the health system.

\section{References}

1. Davis K, Gold M, Makuc D. Access to health care for the poor: Does the gap remain? Ann Rev Public Health 1981;2(1):159-182. [http://dx.doi.org/10.1146/annurev.pu.02.050181.001111]

2. Oliver A, Mossialos E. Equity of access to health care: Outlining the foundations for action. J Epidemiol Community Health 2004;58(8):655-658. [http://dx.doi.org/10.1136/jech.2003.017731]

3. Kong VY, Bulajic B, Allorto NL, Handley J, Clarke DL. Acute appendicitis in a developing country. World J Surg 2012;36(9):2068-2073. [http://dx.doi.org/10.1007/s00268-012-1626-9]

4. Rogers AD, Hampton MI, Bunting M, Atherstone AK. Audit of appendicectomies at Frere Hospital, Eastern Cape. S Afr J Surg 2008;46(3):74-77.

5apaziogas B, Tsiaousis P, Koutelidakis I, et al. Effect of time on risk of perforation in acute appendicitis. Acta Chir Belg 2009;109(1):75-80

6. Heaton KW. Aetiology of acute appendicitis. Brit J Surg 1987;294(6588):1632-1633. [http://dx.doi. org $/ 10.1136 /$ bmj. 294.6588 .1632

Bickell NA Aufses AH Jr. Rojas M Bodian C How time affects the risk of rupture in appendicitis. J Am Coll Surg 2006;202(3):401-406. [http://dx.doi.org/10.1016/j.jamcollsurg.2005.11.016]

8. Boomer L, Freeman I. Landrito E, et al. Perforation in adults with acute appendicitis linked to insurance 8. Boomer L, Freeman J, Landrito E, et al. Perforation in adults with acute appendicitis linked to insura
status, not ethnicity. J Surg Res 2010;163(2):221-224. [http://dx.doi.org/10.1016/j.jss.2010.04.041] status, not ethnicity. J Surg Res 2010;163(2):221-224. [http://dx.doi.org/10.1016/j.jss.2010.04.041]
9. Guagliardo MF, Teach SJ, Huang ZJ, et al. Racial and ethnic disparities in pediatric appendicitis rupture Guagliardo MF, Teach SJ, Huang ZJ, et al. Racia
rate. Acad Emerg Med 2003;10(11):1218-1227.

10. Jablonski KA, Guagliardo MF. Pediatric appendicitis rupture rate: A national indicator of disparities in healthcare access. Popul Health Metr 2005;3(1):4. [http://dx.doi.org/10.1186/1478-7954-3-4]

11. Aguero J, Carter M, May J. Poverty and inequality in the first decade of South Africa's democracy: What can be learnt from panel data from KwaZulu-Natal? J Afr Econ 2007;16(5):782-812. [http:// dx.doi.org/10.1093/jae/ejm015

12. Johna S. The rural surgeon: An endangered species. World J Surg 2006;30(3):267-268. [http://dx.doi. org/10.1007/s00268-005-0465-3]

13. Hsia RY, Mbembati NA, Macfarlane S, Kruk ME. Access to emergency and surgical care in subSaharan Africa: The infrastructure gap. Health Policy Plan 2012;27(3):234-244. [http://dx.doi. org $/ 10.1093 /$ heapol/czr023]

14. Atiyeh BS, Gunn SW, Hayek SN. Provision of essential surgery in remote and rural areas of developed as well as low and middle income countries. Int J Surg 2010;8(8):581-585. [http://dx.doi.org/10.1016/j. ijsu.2010.07.291]

15. Hunter JG. Rural surgery around the world. World J Surg 2006;30:1627.

16. Grimes CE, Law RS, Borgstein ES, Mkandawire NC, Lavy CB. Systematic review of met and unmet need of surgical disease in rural sub-Saharan Africa. World J Surg 2012;36(1):8-23. [http://dx.doi. org/10.1007/s00268-011-1330-1]

17. Ahmed SM, Adams AM, Chowdhury M, Bhuiya A. Gender, socioeconomic development and healthseeking behaviour in Bangladesh. Soc Sci Med 2000;51(3):361-371. [http://dx.doi.org/10.1016/S02779536(99)00461-X]

18. Akande TM, Owoyemi JO. Healthcare-seeking behaviour in Anyigba, North-Central, Nigeria. Research J Med Sci 2009;3:47-51.

19. De Villiers MR. The knowledge and skills gap of medical practitioners delivering district hospital services in the Western Cape, South Africa. SA Fam Pract 2006;48(2):16.

0. Clarke DL, Aldous C. Surgical outreach in rural South Africa: Are we managing to impart surgical skills? S Afr J Med 2013. In press. [http://dx.doi.org/10.7196/SAMJ.7252] 